Volume 12(1) (2015), 1-15

Copyright @ Equinox Publishing Ltd

Sheffield

http://equinoxpub.com

DOI: $10.1558 /$ cam.v11i2.16692

\title{
'Am I anorexic?' Weight, eating and discourses of the body in online adolescent health communication
}

\author{
LOUISE MULLANY ${ }^{1}$, CATHERINE SMITH ${ }^{2}$, KEVIN HARVEY ${ }^{1}$ AND SVENJA ADOLPHS ${ }^{1}$ \\ (1) University of Nottingham (2) University of Birmingham
}

\begin{abstract}
This article explores the communicative choices of adolescents seeking advice from an internet-based health forum run by medical professionals. Techniques from the disciplines of sociolinguistics and corpus linguistics are integrated to examine the strategies used in adolescents' health questions. We focus on the emergent theme of Weight and Eating, a concern which features prominently in adolescents' requests to medical practitioners. The majority of advice requests are authored by adolescent girls, with queries peaking at age 12. A combined quantitative and qualitative analysis provides detailed insights into adolescents' communicative strategies. Examinations of question types, register and a discourse-based analysis draw attention to dominant discourses of the body, including a 'discourse of slenderness' and a 'discourse of normality', which exercise negative influences on adolescents' dietary behaviours. The findings are of applied linguistic relevance to health practitioners and educators as they provide them with access to adolescents' health queries in their own language.
\end{abstract}

Keywords: corpus linguistics; discourses of the body; eating disorders; electronic discourse; sociolinguistics

\section{Introduction}

The Teenage Health Freak (henceforth THF) has been running successfully as a computermediated communicative resource for adolescents since 2000 . It was launched by medical specialists in child and adolescent health in response to various difficulties that adolescents experience when communicating in face-toface settings with healthcare professionals (McPherson 2005; Harvey et al. 2008). The website is designed to be interactive, confidential and evidence-based, providing adolescents with advice and information on a broad range of health issues in accessible, non-technical language.

This article focuses on a corpus of 113,480 advice requests totalling just over 2 million words, sent to the website from 2004-2009. Due to the global nature of a freely available website we cannot make precise demographic claims about the nature of the users, but as an English-language-based resource it is likely to be accessed by a wide range of young people, predominantly from Anglophone countries and the UK in particular. This study combines corpus linguistic tools and techniques with a sociolinguistic analysis of age and gender with specific reference to the emergent topic of Weight and Eating. It investigates the linguistic strategies that adolescents use to express their health concerns in their own terms, integrating a lexicogrammatical analysis of register and question types with an analysis of dominant discourses of the body. The next section introduces the value of studying computer-mediated communication. Section 3 outlines the importance of studying age, gender and discourses of the body. The methodology is outlined in Section 4, followed by data analysis in Section 5 . The implications of 
the findings are then discussed, followed by an overall conclusion, which highlights the applied linguistic value of this work.

\section{Computer-mediated health communication}

Electronic exchange is now a well-established area of investigation in a range of healthcare settings (Locher 2006; Miah and Rich 2008; Harvey 2013; Harvey et al. 2008). One advantage of electronic communication for discussing medical concerns can be its disembodied manner, with the medium protecting advice-seekers' identities. Users of electronic communication can display 'remarkable candour in the information they're willing to divulge online' (Baron 2000: 234). Clinicians, researchers and everyday internet users have noted how people can communicate differently in cyberspace: 'they loosen up, feel less restrained, and express themselves more openly' (Suler 2004: 321). However, this is not to suggest that individuals can entirely abandon their identities or bodies (see Miah and Rich 2008). But what we would argue is that electronic communication constitutes an invaluable resource, offering an appealing alternative for adolescents from face-to-face encounters to talk about personal and/or potentially embarrassing topics (McPherson 2005; Harvey 2013).

A key feature of $T H F$ is its electronic messaging facility, 'Dr Ann's Virtual Surgery'. This communicative form is akin to email, without the need to use an individual email account responses are posted to the website. This allows advice-seekers to submit health questions electronically and in confidence to the online doctor, 'Dr Ann'. Dr Ann is a persona for a team of dedicated General Practitioners who are responsible for providing advice. Any personal information that is disclosed is removed, and all users are thus ensured complete anonymity when advice-seeking via $T H F$. This provides far more communicative freedom than face-toface settings, reducing embarrassment while providing a secure platform from which to ask awkward, sensitive or detailed questions without the fear of being judged or stigmatised (Cotton and Gupta 2004). It also provides access to data demonstrating what adolescents really want to ask about health in their own language, rather than having concerns elicited by researchers. This project was carried out in collaboration with the Dr Ann team. We were given access to the entire submitted corpus, not just those messages that received answers and appeared on the website. This enabled us to study the full range of queries submitted.

Given the large influx of messages that the site receives on a daily basis $(52,864$ on average per day), it is not possible for the team to respond to all requests, although the team aims to respond to a very broad range of topic areas. The $T H F$ interface asks contributors for self-reports of age and gender, but this is optional - responses are still posted regardless of whether advice-seekers provide such details. Nearly $90 \%$ of contributors provide age and/or gender information.

\section{Age, gender and discourses of the body}

A focus on adolescence as a significant age category is long-established within sociolinguistics and researchers have also successfully combined a focus on gender and age (e.g. Eckert 2000). The category of 'adolescence' is broken down into numerical ages in this study, as the website gives adviceseekers the option of self-selecting a specific age category. Respondents have the following options: under $10,11,12,13,14,15,16$ or 17 . While the accuracy of the age category relies upon self-report, these can be of particular interest when examined alongside a linguistic analysis to show at which age particular health concerns/questions become salient for young people. This has the potential to pinpoint the age at which certain types of health education should be given within school curricula, using adolescents' questions - which very often demonstrate a lack of knowledge/information - as a guide.

Health and illness are partially constructed, reproduced and perpetuated through discourse (Coupland and Gwyn 2003) and it is well-established within sociolinguistic gender studies to follow Foucault's definition of discourse as 'practices that systematically form the objects 
of which they speak' (1972: 49). Application of this definition has been particularly influential in producing analyses of dominant gendered discourses that operate at an overarching, societal level (Mullany 2007). Furthermore, as Butler (1993) has demonstrated, the body cannot be talked about without discourse. Butler's theorisations have shown how 'every reference to the body will construct the body in some way' (Jeffries 2007: 21). We argue that this approach to identifying dominant discourses presents an effective means of analysing the issues that affect adolescent advice-seekers.

In developed nations, exceptional value is placed on thinness, which can lead to extreme dieting and weight restriction practices (Treasure et al. 2010: 586). Although young women and men have anxieties about body image which have become normalised, research indicates that girls and young women place far more emphasis on bodily attractiveness. Banyard (2010) reports that eating disorders can be seen as a crystallisation of gender and culture in contemporary society, embodying dominant ideals. Female bodies are seen as 'inanimate objects to be publicly scrutinised, judged, maintained, manipulated for the benefit of others; they are shared public property' (Banyard 2010: 19-20).

In contemporary western societies body objectification is at an all-time high, with increasing pressure for body manipulation and recourse to surgery; practices that can be viewed as part of body 'technologisation' (Jeffries 2007). The mass media promote an idealised slender shape which, owing to genetics and physiology, few women can actually attain (Lupton 2013). One of the many consequences of this discourse, which we have termed the 'discourse of slenderness', is that it invites individuals to compare their bodies with this idealised slender shape. It equates slenderness with beauty and goodness and fatness with self-indulgence and absence of control (Lupton 2013). The prevalence of such a discourse in western societies emphasises the importance of examining young people's communication surrounding weight-related issues. There is a correlation between women's exposure to media representations of slender ideals and reported dissatisfaction with their own bodies
(Jeffries 2007). This problem has also been exacerbated by the current media obsession with the global 'obesity epidemic' (Lupton 2013), which has contributed further to the stigmatisation of fatness. Exposure to thinness-promoting media images increases the risk of body dissatisfaction and is associated with increases in eating disorders (Groesz et al. 2002).

Adolescence is a period when comparison with others plays a vital part in self-perception (Groesz et al. 2002: 2), and body size is intimately linked to self-esteem. Adolescents who are over-weight are more likely to experience adjustment problems and bullying by peers (Fox and Farrow 2009; Harris 2010). Bullying and teasing which centres around body size increases the risk of developing an eating disorder. As Treasure et al. (2010: 586) observe, 'The tension between the stigmatisation of fatness [and] idealisation of thinness [...] could lead to weight control behaviours that can have a destabilising effect on the biology of appetite control.' The prevalence of such dominant discourses surrounding Weight and Eating emphasises the importance of analys-ing first-hand accounts of concerns over Weight and Eating issues.

\section{Methodology}

The THF data pre-existed the commencement of this project, although adolescents are informed that their advice requests will be used for a range of academic research purposes in future. By posting online, adolescents are informed that their messages may be used for academic research purposes by the research team and their partners, but that full anonymity is always guaranteed (see Harvey 2013). A breakdown of the corpus by gender $^{1}$ including average message length is shown in Table 1:

Females send more messages to the website than males and their messages are on average much longer. Females contribute over twice as many words in the corpus than males. 'Gender unspecified' messages account for $10 \%$ of the overall number; they are also much shorter and make up an even smaller percentage of the overall words in the corpus (5\%). 
Table 1. Summary of the corpus by gender and message length

\begin{tabular}{lcccc}
\hline & All & Male & Female & Unspecified \\
\hline Total Messages & 113,480 & 41,830 & 59,884 & 11,766 \\
& & $(37 \%)$ & $(53 \%)$ & $(10 \%)$ \\
Total Words & $2,217,919$ & 667,277 & $1,442,784$ & 107,858 \\
& & $(30 \%)$ & $(65 \%)$ & $(5 \%)$ \\
Median Message Length & 10 & 8 & 13 & 6 \\
\hline
\end{tabular}

Corpus linguistic methodologies constitute a robust approach to health communication (Locher 2006; Harvey et al. 2008; Charteris-Black and Seale 2010). As a way into this substantial dataset and to provide a survey of the salient health themes, the first stage of the analysis involved identifying 'keywords'. Keywords are an indicator of expression and content (Seale et al. 2007) and have been adopted as a reliable means of identifying key themes in health language corpora (eg. Seale et al. 2007; Harvey 2013). In this sense, a 'keyword' is one that is statistically more frequent, rather than the usual sense of words deemed to be of significant sociocultural importance. The advantage of using statistical keywords is that they remove $a$ priori biases of the analyst from the identification of themes of significance/interest. Keywords present evidence that a conventional thematic qualitative analysis might obscure, thus identifying salient themes that warrant further exploration in context. We used the 100-million word British National Corpus (BNC) as the reference corpus. Keywords presented in the paper are therefore words that occur with a statistically greater frequency in the THF corpus than the BNC.

The corpus does not contain an equal number of messages from males and females or different age groups (see Table 1). It is thus not possible to make direct comparisons between the different demographics using raw frequency data alone. Following corpus linguistic principles, to draw comparisons the data needed to be normalised by the amount of messages received from the demographics in question (Baker 2010: 19-21). To take account of the underlying imbalance in messages these frequency counts can be normalised by number of messages. In this case we are using 1,000 messages as the unit of normalisation.
We take a three-stage analytical approach. We begin with an initial survey generated by keyword analysis, which includes analyses of register. We then continue to use corpus techniques but move towards a qualitative paradigm by surveying the question types adolescents use, which works to highlight gaps in adolescents' medical knowledge. As the key purpose of Dr Ann's surgery is to present adolescents with the opportunity to ask a health question online, analysis of different question types that adolescents use seems to be an important category of communicative analysis. We integrate this with an analysis of dominant discourses of the body, focusing in particular upon messages relating to anorexia and bulimia. We believe that the integration of these approaches demonstrates the complementary nature of corpus analysis and discourse-based analysis (see also Harvey 2013).

\section{Analysis}

\subsection{Keywords and topics}

Keywords were generated via WordSmith Tools (Scott 2008) using the log likelihood statistic with a probability value of $<0.000001$, the default value used by the WordSmith software. Accepted practice in corpus linguistics is that a $\mathrm{p}$ value of $<0.05$, which indicates a confidence of $95 \%$ that the result has not arisen by chance, is the base mark of acceptability and thus worth reporting (McEnery et al. 2006). The p value threshold 0.000001 set by WordSmith is comparatively lower, which means that there is a one in a million chance that the keyness reading is down to error. Although this threshold results in fewer keywords being obtained, Scott (2008) 
argues that the notion of risk is less important than selectivity: such a low value will produce a more manageable number of keywords, as well as a total amount which is far less likely to have resulted owing to chance. In total, over 2,000 keywords were generated by this procedure to highlight the 'aboutness' of the corpus. When the full keyword list is taken into account, five main themes emerge from the data, as illustrated in Table 2. 'Types' refers to the number of different words (or word forms) classified in the topic. 'Tokens' refers to the total number of instances of all the types present in the data.

Although Sex/Pregnancy/Relationships is by far the most popular category, all five of these main themes have proved to be important topics of analysis (Adolphs et al. 2012). Weight and Eating contains on average the longest messages of all the topics, suggesting that these advice requests (along with Body Changes) are more detailed than some of the larger topics.

Table 3 shows the 40 keywords classified in the Weight and Eating theme. The analysis in this article is based upon messages containing at least one of these keywords.
The keyword list highlights how adolescents' messages are focalised around eating behaviours and diet, including eating disorders, and the interrelated issue of weight. There is evidence of a mixture of registers, ranging from colloquial register (e.g. 'skinny', 'chubby', 'flabby', 'veggie'), a general health register ('weight,' 'exercise' and 'diet') and a technical medical register ('BMI', 'anorexic'/'anorexia', 'bulimic'/'bulimia' and 'obese'). The presence of technical medical register indicates that adolescents requesting advice on these topics have, at the very least, an awareness of the existence of such terms. The different registers that can be seen in the keyword list thus begin to give some insight into the issues that are of most concern to adolescents and point to areas where they require health advice.

By examining keywords in context we can observe how these terms are being used - are they requests for definition, demonstrating vocabulary knowledge but lack of semantic understanding, or is definition already achieved? If working knowledge of the technical terms is observable, what other requests are made? What can adolescents' language choices reveal in terms of the

Table 2. Topical keyword summary

\begin{tabular}{lccc}
\hline Topic & Types & Tokens & Median Length \\
\hline Sex/Pregnancy/Relationships & 166 & 62,804 & 13 \\
Sexual Body Parts & 80 & 24,492 & 13 \\
Body Changes & 37 & 14,754 & 18 \\
Weight and Eating & 40 & 12,703 & 19 \\
Smoking/Drugs/Alcohol & 46 & 11,796 & 10 \\
\hline
\end{tabular}

Table 3. Keywords from the THF corpus classified under Weight and Eating

\begin{tabular}{|c|c|c|c|c|c|c|c|}
\hline 1 & WEIGHT & 11 & ANOREXIA & 21 & DIETING & 31 & FLABBY \\
\hline 2 & FAT & 12 & DIET & 22 & SLIM & 32 & VEGGIE \\
\hline 3 & EAT & 13 & BULIMIC & 23 & CALORIES & 33 & FLAB \\
\hline 4 & WEIGH & 14 & EXERCISE & 24 & THINNER & 34 & WEIGHS \\
\hline 5 & EATING & 15 & OBESE & 25 & FOODS & 35 & VEGAN \\
\hline 6 & SKINNY & 16 & BULIMIA & 26 & SKINNIER & 36 & BINGEING \\
\hline 7 & OVERWEIGHT & 17 & THIN & 27 & LAXATIVES & 37 & ATE \\
\hline 8 & ANOREXIC & 18 & FATTER & 28 & FATTY & 38 & STARVE \\
\hline 9 & BMI & 19 & CHUBBY & 29 & HUNGRY & 39 & VEGETARIAN \\
\hline 10 & UNDERWEIGHT & 20 & EATS & 30 & DIETS & 40 & SNACKING \\
\hline
\end{tabular}


depth of knowledge on these topics? Broadening the analysis to examine keywords in context will enable a fuller exploration and help pinpoint the exact questions advice-seekers want answering when using such registers. (see Section 5.2.1).

It is useful to continue with a quantitative survey based on the 40 keywords to examine distribution in relation to age and gender. Figure 1 shows that Weight and Eating is a persistent concern throughout the adolescent years. Over 60 messages per 1,000 sent by $11-16$ year olds are concerned with this topic. However, there is an observable peak at age 12 , where occurrences jump to 78 per 1,000 messages. $^{2}$

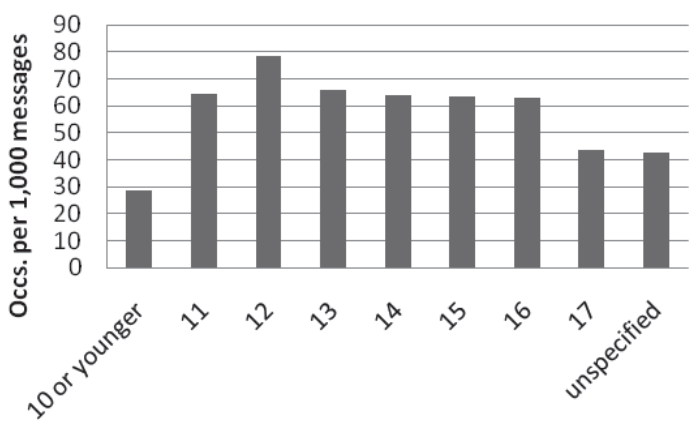

Figure 1. Occurrences of Weight and Eating messages by age (normalised per 1,000 messages)

Females ask more than 2.5 times the number of questions than males (78.59 compared to 30.93 per 1,000 messages). The messages sent by females are almost twice as long on average (24 words compared to 13 words). Although Weight and Eating is a much lesser concern for male writers, Figure 2 shows that they also have a peak around age 12 , with a second, smaller increase around age $16 .^{3}$

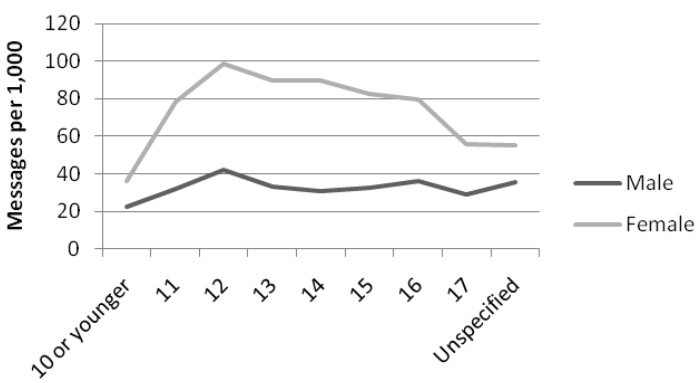

Figure 2. Occurrences of Weight and Eating messages by age and gender (normalised per 1,000 messages)
There are potential implications here for health practitioners/educators deciding on the age at which education regarding diet, nutrition and eating behaviours is given. Within school curricula this can be informed by examining the knowledge gaps that adolescents have displayed. Evidence of the registers and styles that adolescents choose when seeking advice on Weight and Eating can reveal pertinent information about their comprehension of (or lack of) medical knowledge.

\subsubsection{Question types}

While the overview above provides an orientation to the theme of Weight and Eating and its distribution, it does not provide insight into the question types being asked about the topic. The corpus linguistic technique of question formulas was used to extract direct questions from the messages. Question formulas were selected from the top 200 two-word clusters in the corpus. This list was further reduced after examination, as some clusters were used primarily as tag questions. The resulting list of question-forming clusters (in raw frequency order) is as follows:

- What is

- What should

- How do

- What do

- How can

- What can

- Why do

- What are

- What does

Ten-word chunks beginning with any of these two-word clusters were extracted. These chunks were then manually analysed and classified into prototypical question types. The top ten question types are shown below, with typical illustrative examples. ${ }^{4}$

1. What is the average/normal weight for $\mathrm{x}$ ? what should my weight be (male, 12)

2. How can I lose weight? what is the best way to lose weight really quickly (female, 13) 
3. What is a healthy diet? how can i plan a healhy diet (gender and age unspecified)

4. How can I put on weight? what can $i$ eat that can help me put weight - (male, 17)

5. What is good exercise? what is the best type exercise - (male, 12)

6. What is bulimia?

All as prototype question

7. How do I get slim/skinny how do I get slimmer - (female, 14)

8. What is anorexia? All as prototype question

9. How can I tone my tummy? how can i get a flat tummy - (female, 12)

10. What is my BMI? All as prototype question

The above data demonstrate how question formula analysis pinpoints areas where there is a lack of knowledge from the enquirer. Question 1 shows that, although adolescent adviceseekers are aware of the notion of an 'average' or 'normal' body size, they often do not know what a reasonable weight is for them at their stage of development. Not knowing one's 'ideal' weight can potentially lead to individuals perceiving themselves to be overweight (or underweight) when in fact they are of healthy body size. Among young women in particular, there is often a discrepancy between objective and subjective impressions of excess weight (Banyard 2010).

Questions of the 'What is the average/normal weight' type and 'what is my BMI?' presuppose a normative expectation of body weight. Such an expectation can work to regulate behaviour, or at the very least intimate concern (Jutel 2006). Although the fourth-most popular question type is requesting information on how to put on weight, five out the top ten question categories $(2,6,7,8$ and 9) focus on the theme of weight reduction. Similar to question categories 1 and 10, the five categories of weight reduction signal a normative expectation, attributing a slender, weight-reduced body to some 'normative appearance in health' (Jutel 2006: 2268) - the discourse of slenderness is very much in evidence here.
To look more in-depth at Weight and Eating and use of technical medical register, a sub-corpus focusing on disordered eating behaviours was selected. As witnessed in the keyword analysis, the technical medical register 'anorexia'/'anorexic' and 'bulimia'/'bulimic' occur in the top 20 keywords. Examination of question types has shown that the most frequent questions on anorexia and bulimia are requests for definition (numbers 6 and 8 in the top ten); despite awareness of the medical register, knowledge of how they are applied and used for diagnosis is often unknown. Another important reason for selecting eating disorders as a subset is that medical sources have consistently highlighted anorexia and bulimia as the most serious and persistent illnesses suffered by adolescents in connection with Weight and Eating (Harris 2010).

\subsubsection{Anorexia and bulimia}

All messages containing at least one instance of 'anorexia'/'anorexic', 'bulimia'/'bulimic' were extracted from the full set of Weight and Eating messages. Two subsets were created: 430 anorexia messages and 120 bulimia messages. At this stage, most studies using a corpus methodology examine concordance lines, using a span of four words on either side of the keyword, to study patterns surrounding particular keywords of interest. In this case, perhaps due to the typically short nature of text found in all $T H F$ data, concordance lines were not found to be a useful unit for analysis. It became clear that the broader context of the full message needed to be examined in order to produce a meaningful analysis of communicative strategies. Initial lexical instances were surveyed and quantified, and these were then combined with analyses of whole messages. Numbers are provided here just to give an idea of the differences between message types, but it is the message types themselves that are the more important aspect. They are grouped into broad themes.

The first theme is 'general requests for information' on anorexia and bulimia (Table 4). These account for a quarter of anorexia messages and over a quarter of all bulimia messages. Many of these use the question formulae investigated 
demonstrates knowledge gaps surrounding the medical register.

The next topic comprises 'requests for diagnosis' from Dr Ann (Table 5). These are typically longer and often include brief descriptions where advice-seekers summarise their eating behaviours. Here, adolescents are searching for information and clarification as to whether Dr Ann thinks they are suffering from anorexia or bulimia. Around a quarter of messages concerning anorexia are classified in this topic compared with $15 \%$ of bulimia messages.

The first classification of messages is straightforward requests for diagnosis, making up the majority of messages for both categories. The second is similar but refers to 'starting to become' anorexic. There is evidence here of the text-producer seeking expert advice to assess whether or not the diagnostic medical register can be legitimately applied, as in Example 1.

Table 4. Summary of messages containing general requests for information

\begin{tabular}{lcc}
\hline & $\begin{array}{c}\text { Percentage of } \\
\text { anorexia messages }\end{array}$ & $\begin{array}{c}\text { Percentage of } \\
\text { bulimia messages }\end{array}$ \\
\hline Word only & 7.2 & 4.2 \\
What is & 2.6 & 11.7 \\
What are the causes of & 4.9 & - \\
What are the effects of & 3.2 & 8.3 \\
Signs/Symptoms & 1.9 & 0.8 \\
Why do you get & 3.3 & 0.8 \\
General info about (inc statistics) & 2.1 & 2.5 \\
TOTAL & 25.2 & 28.3 \\
\hline
\end{tabular}

Table 5. Summary of messages containing requests for diagnosis

\begin{tabular}{lcc}
\hline & $\begin{array}{c}\text { Percentage of } \\
\text { anorexia messages }\end{array}$ & $\begin{array}{c}\text { Percentage of } \\
\text { bulimia messages }\end{array}$ \\
\hline Am I/I think I am & 15.6 & 11.7 \\
Starting to become & 0.9 & - \\
They say & 1.9 & - \\
They say, am I & 5.1 & 0.8 \\
They say, I'm not, am I & 1.2 & - \\
TOTAL & 24.7 & 12.5 \\
\hline
\end{tabular}


Example 1

hi dr ann. i no only mostly girls get it but $\boldsymbol{i}$ think $\boldsymbol{i}$ might becoming bulimic. i'm always deprsted and i've been going to the gym 5 time a week for a couple of hours. i'm not bulimic yet because i don't no how to vomit food out (male, 13)

Following a greeting, the advice-seeker issues a declarative, stating his knowledge that bulimia is a condition which 'mostly' affects girls, but that he thinks he may be becoming bulimic, albeit introduced with hedging and modality ('think', ' $m i g h t$ '), arguably operating as face protection devices, which leaves space for Dr Ann to confirm diagnosis. He provides a short report of his behaviour, supporting his need for an expert opinion by drawing attention to potential comorbidity, not an uncommon characteristic of eating disorders (Treasure et al. 2010), using an intensifier ('always') to strengthen his subject position. In declaring his lack of proficiency in rejecting food ('idon't no how to vomit food out'), he arguably presents eating disorders as learned behaviours, conditions that have to be mastered to be 'legitimately' identified as bulimic.

In both cases the suggestion of diagnosis comes from the enquirers themselves. The remaining three classes ('They say') all contain a degree of external involvement. Using the technique of reported speech, advice-seekers state that a third-party has labelled them as having an eating disorder. This strategy helps to justify adolescents claims to seek expert advice, which in itself is face-threatening (Morrow 2006), particularly for stigmatised health conditions. It also operates as a distancing device, protecting face by enabling the advice-seeker to question, disagree or deny that they have the eating disorder ascribed to them by others.

Example 2 provides an illustration of a they say' message.

\footnotetext{
Example 2

hello, in 13 and a male and like my friends all say $i$ 'm anorexic and all this rubbish and i'm not i must admit i feel so fat and ugly. i swim m many times a week but i just i don't no most of the people are so thin and mustly i'm 7 stone 3 pounds and i don't no if $i$ am but i really do want to loose wait but i still eat stuff :( help! (male, 13)
}

The male advice-seeker reports his friends' application of diagnostic medical register to describe his behaviour. He immediately dismisses this subject-positioning through use of a colloquial register, providing a direct stylistic contrast with his own presentation of his friends' perspective. He re-categorises medical register pejoratively as 'all this rubbish', followed immediately with a direct, on-record denial, 'im not', operating as a face-saving strategy. However, he then goes on to issue a declarative which negatively evaluates his body (' $i$ feel so fat and ugly'), before using quantification rhetoric to detail his body weight, inviting Dr Ann to provide a diagnosis. He then declares doubt over whether he is anorexic, contradicting his earlier denial by expressing uncertainty ('I don't know if I am'). Again, there is evidence here of the confusion advice-seekers feel when trying to work out whether or not they could be medically diagnosed as anorexic or bulimic.

In addition to the 'they say' messages operating as face-saving strategies and legitimating claims to seek professional medical advice, these messages can demonstrate the influence of the perceptions and judgements of others over the individuals' constructions of themselves. The body is perceived as something external and foreign - more relevant to others than the individual. Yet, for some young people, eating disorders are tied up with notions of personal agency and control. According to theorists such as Lupton (2003), the body is the only sphere over which, by reducing weight, some adolescents can exert some personal control, a theme which recurs throughout a number of messages and can be seen through the quantification register and detailed reports of dietary routines.

The next set of communicative features relate to either adolescents who have already had some form of 'official' medical diagnosis but are still searching for information, or those who have self-diagnosed. We have termed this the 'postdiagnosis' category (Table 6).

A number of these messages communicate the writer's desire to have an eating disorder, thereby adopting an 'anti-recovery' perspective (Fox et al. 2005). This is seen in Example 3. 
Table 6. Post-diagnosis issues

\begin{tabular}{lcc}
\hline & Anorexia & Bulimia \\
\hline I am (possible self diagnosis) & 3.2 & 3.3 \\
Diagnosed & 5.1 & - \\
Treatment & 0.5 & 8.3 \\
Complications & - & 4.2 \\
TOTAL & 8.8 & 15.8 \\
\hline
\end{tabular}

Example 3

I want to look anorexic. I know its really 'stupid,' but $\mathrm{i}$ like the idea of being able to see my bones. I've started restricting my calorie intake to around 650 a day, and eating mostly negative calorie foods. Also i CandS (Chew and spit) and i've tried purging (but for some reason i can't do it). what's going on with me. I feel stupid for wanting to look like that because $\mathrm{i}$ know its dangerous, but i want it.

Adolescents communicate a desire for their body image to be anorexic. There is evidence of the discourse of slenderness, with adolescents aspiring to ultra-thin bodies. If adolescents construe eating disorders as enviable lifestyle choices, they are still recognised through the register of diseases or deleterious activities. Example 3 illustrates this, with the writer first presenting as a rational, informed individual, yet unable to resist an extreme diet. As this and other messages suggest, ideologies promoting a dominant discourse of slenderness of the 'perfect' body are arguably influencing adolescents' self-perceptions and eating behaviours.

\section{Discussion}

The linguistic analysis highlights where knowledge gaps are for adolescents surrounding Weight and Eating issues and how they articulate the problems they experience through the communicative choices they make, as well as the ages at which such questions emerge. These requests provide evidence of the difficulties and confusion adolescents face due to discourses of the body, and the dominant discourse of slen-derness in particular. The dominant discourse of slenderness underlies messages that request knowing how to be a 'normal' body size, body image concerns, difficult relationships with food and the difficulty of freely discussing these sensitive matters. These personal insights offer a counterweight to much psychiatric research literature which takes little account of the personal and social contexts of emotional distress (Rogers and Pilgrim 2005), thus enhancing our understanding of adolescent health communication in their own language.

It is also possible to interpret the concerns over what constitutes a 'normal' or 'healthy' body size as a potential critique by adolescents of medically-sanctioned 'normality'. The extent to which adolescents may be critiquing norms is difficult to assess here due to the specific, adviceseeking nature of the dataset, though research on adolescent online communication including blogs and forums suggests that this may well be the case - evidence of resistant discourses and a critique of societal norms can be witnessed in studies that analyse pro-anorexia blogs and forums (Bond 2012).

The keyword analysis reveals that Weight and Eating-related issues are a prominent concern for young women. These preoccupations arguably reflect the predicaments of young women in western societies, who, consistently exposed to mass media gender ideologies and the dominant discourse of slenderness, are encouraged to equate an idealised slenderness with beauty and success. As Appignanesi (2008: 431) puts it:

Constant warnings from health authorities [...] the fashion and diet industries - both worth billions - have all combined to create a situation in which fat is, for many girls, a nearer and greater terror than war; while thin is perfection, a dream sphere to be sought in which all problems will magically vanish. (Appignanesi 2008: 431)

Dominant discourses of the body appear to have a powerful hold over the advice-seekers, particularly in the analysis of anorexia and bulimia messages (including a handful of young men). Many advice-seekers articulated disquiet with present body sizes and expressed desires to be much thinner. Anorexia was often not considered an illness (and therefore something which needed treatment), but a sought-after goal, a lifestyle choice. This study thus offers evidence 
that young people experience pressures to reduce body weight in pursuit of a fashionable slender ideal.

As with previous research, we argue that the media play a key role in maintaining dominant discourses of the body, thus contributing to young women's images of themselves (Department of Health 2008). If the media presented more diverse selections of body shapes and sizes this would not only take some pressure off adolescents to partake in extreme dietary behaviours, but also hopefully reduce peer-pressure to strive for an unrealistic body size.

The analysis has illustrated how Weight and Eating requests peak at age 12 for both females and males, suggesting that questions requesting information and concerns over diet and body appear to affect adolescents earlier than requests on other topics, with questions in the rest of the corpus peaking at age 14. This highlights the importance of health providers routinely discussing weight and nutrition concerns with younger adolescents, engaging in an educational dialogue that emphasises a positive body image and appropriate eating and exercise behaviours (Neumark-Sztainer and Hannan 2000: 575).

The adolescents in this study sought answers to a variety of Weight and Eating-related matters. Analysis of question types revealed a set of commonly recurring enquiries that invoked 'normal' weight, often alluding to an abstract, ideal body against which their own sizes were contrasted. In the majority of cases these question types indicated a desire on the part of the adolescents to lose weight, articulating, by implication, unhappiness with current size, perceived to depart from an unknown standard. These messages thus demonstrate not only the pressures on young people to regulate weight, but also their difficulty in establishing what precisely constitutes a physical norm, with 'What is the average/normal weight for $\mathrm{x}$ ?' being the most common question. Used universally to calculate body fat, the Body Mass Index (BMI) has been critiqued for objectifying measurement (Jutel 2006), as if quantification itself were neutral and incontrovertible (anything below/over a certain measurement is de facto aberrant). However, adolescents' questions expressed uncertainty with official weight measurements, including BMI. For example, even though their weights were sometimes described as falling within a normal body size, they were still liable to perceive themselves as overweight. As one adviceseeker put it: 'My BMI is 23. 4 [an acceptable body size according to the BMI]. I see this as indicating I am the fat side of healthy, but my friends all say I'm slim.'

To some extent, messages like these support the view that normal and abnormal weight sizes are socially constructed (Lupton 2013). It is not only technical, clinical judgements that determine an acceptable, 'healthy' body size, but also personal and social assessments. For some adolescents, measurements such as BMI mean little in the face of more pressing social judgements. Despite the elusive nature of acceptable body weight, discourses of normality significantly influence young people's dietary and exercise regimens. To some extent, the concern with normality can also be seen as a reflection of the developmental stage of adolescence, during which teenagers are likely to be occupied with personal identity formation and resolving identity issues (Eckert 2000). Fashioning an identity for oneself during this time involves seeking acceptance - abiding by the dominant discourse of slenderness has become a requisite for achieving social acceptance in some groups, with notions of body 'normality' underpinning such approval.

\section{Conclusion}

A key aim of this study has been to highlight the value of analysing computer-mediated health communication. As Rich (2006: 320) argues, if we are to enhance our understanding of the relationship that young people have with eating disorders, we need to develop appreciation of such complexities. In examining the communicative strategies through which adolescents articulate concerns about weight and eating, our analysis exposes patterns and discourses through which young people perceive, make sense of and experience disordered eating. Websites such as $T H F$ provide young people with a platform from 


\section{Louise Mullany, Catherine Smith, Kevin Harvey and Svenja Adolphs}

which to ask doctors questions which they would be unlikely to pose face-to-face. Many young people are increasingly turning to the internet as a source of health advice and information (Suzuki and Calzo 2004). Accordingly, electronic health communication datasets present a unique linguistic resource for analysing adolescents' health concerns.

By combining quantitative and qualitative analyses, we have found patterns and commonalities in adolescent language use when asking questions on Weight and Eating, along with identifying knowledge gaps and dominant discourses of slenderness and normality. The findings are of applied linguistic value and they are currently being used to inform the work of healthcare practitioners and educators working with young people (see Adolphs et al. 2012).

\section{Acknowledgement}

Research reported in this article was funded by the Economic and Social Research Council, RES-000-22-3448.

\section{Notes}

1. If the overall corpus is examined for all topics, questions peak at the age 14 for both males and females. Questions on Weight and Eating therefore peak two years earlier than the average peak.

2. Although technically 'sex' is reported, as gender is the term used by the website providers and the one adolescents have seen, it is the term that we use here.

3. Messages from unspecified genders have been omitted as the total numbers are so small.

4. Messages are cited with original spelling errors. For discussion of the analytical consequences of these spelling errors see Smith et al. (2014).

\section{References}

Adolphs, S., Mullany, L., Harvey, K. and Smith, C. (2012) Am I Normal? What Adolescents Want to Know About Health. Health Education Booklet. Nottingham: University of Nottingham.
Appignanesi, L. (2008) Mad, Bad and Sad: A History of Women and the Mind: Doctors from 1800 to the Present. London: Virago Press.

Baker, P. 2010. Corpus Linguistics and Sociolinguistics. Edinburgh: Edinburgh University Press.

Banyard, K. (2010) The Equality Illusion: The Truth about Women and Men Today. London: Faber.

Baron, N. (2000) Alphabet to Email: How Written English Evolved and Where it's Heading. London: Routledge. http://dx.doi.org/10.4324/9780203194 317

Butler, J. (1993) Bodies that Matter: On the Discursive Limits of Sex. New York: Routledge.

Charteris-Black, J. and Seale, C. (2010) The Language of Gender and Illness. Basingstoke, UK: Palgrave. http://dx.doi.org/10.1057/9780230281660

Cotton, S. and Gupta, S. (2004) Characteristics of online and offline health information seekers and factors that discriminate between them. Social Science and Medicine 59 (9): 1795-1806. http:// dx.doi.org/10.1016/j.socscimed.2004.02.020

Coupland, J. and Gwyn, R. (eds) (2003) Discourse, the Body and Identity. Basingstoke, UK: Palgrave.

Department of Health (2008) Healthy Weight, Healthy Lives: A Cross-Government Strategy for England. London: Department of Health.

Eckert, P. (2000) Linguistic Variation as Social Practice. Oxford: Blackwell.

Foucault, M. (1972) The Archaeology of Knowledge. Translated by A. M. Sheridan Smith. London: Tavistock Publications.

Fox, C. and Farrow, C. (2009) Global and physical self-esteem and body dissatisfaction as mediators of the relationship between weight status and being a victim of bullying. Journal of Adolescence 32 (5): 1287-1301. http://dx.doi.org/10. 1016/j.adolescence.2008.12.006

Fox, N., K. Ward and A. O'Rourke 2005. Pro-anorexia, weight-loss drugs and the internet: An 'antirecovery' explanatory model of anorexia. Sociology of Health and Illness 27 (7): 944-971. http:// dx.doi.org/10.1111/j.1467-9566.2005.00465.x

Groesz, L., Levin, M. and Murnen, S. (2002) The effect of experimental presentation of thin media images on body satisfaction: A meta-analytic review. International Journal of Eating Disorders 31 (1): 1-16. http://dx.doi.org/10.1002/eat.10005

Harris, E. 2010. Diet, Nutrition and Eating Behaviours. AYPH Research Update. London: Association of Young Person's Health.

Harvey, K. (2013) Investigating Adolescent Health Communication. London: Bloomsbury.

Harvey, K., Churchill, D., Crawford, P., Brown, B., Mullany, L., Macfarlane, A. and McPherson, A. 
(2008) Health communication and adolescents: What do their emails tell us? Family Practice 25 (4): 304-311. http://dx.doi.org/10.1093/fampra/ cmn029

Jeffries, L. (2007) Textual Construction of the Female Body. Basingstoke, UK: Palgrave. http://dx.doi. org/10.1057/9780230593626

Jutel, A. (2006) The emergence of overweight as a disease entity: Measuring up Normality. Social Science and Medicine 63 (9): 2268-2276. http:// dx.doi.org/10.1016/j.socscimed.2006.05.028

Locher, M. (2006) Advice Online. Amsterdam: Benjamins. http://dx.doi.org/10.1075/pbns.149

Lupton, D. (2003) Medicine as Culture. Second Edition. London: Sage.

Lupton, D. (2013) Fat. London: Routledge.

McEnery, A., Xiao, R. and Tono, Y. (2006) CorpusBased Language Studies. London: Routledge.

McPherson A. (2005) ABC of Adolescence: Adolescents in primary care. British Medical Journal 330 (7489): 465-467. http://dx.doi.org/10.1136/bmj. 330.7489 .465

Miah, A. and Rich, E. (2008) The Medicalisation of Cyberspace. London: Routledge.

Morrow, P. R. (2006) Telling about problems and giving advice in an Internet discussion forum: Some discourse features. Discourse Studies 8 (4): 531-548. http://dx.doi.org/10.1177/1461445606 061876

Mullany, L. (2007) Gendered Discourse in the Professional Workplace. Basingstoke, UK: Palgrave. http://dx.doi.org/10.1057/9780230592902

Neumark-Sztainer, D. and Hannan, P. J. (2000) Weight-related behaviors among adolescent girls and boys. Archive of Paediatric Adolescent Medicine 154 (6): 569-577. http://dx.doi.org/10.1001/ archpedi.154.6.569

Rich, E. (2006) Anorexic dis(connection): Managing anorexia as an illness and identity. Sociology of Health and Illness 28 (3): 284-305. http://dx.doi. org/10.1111/j.1467-9566.2006.00493.x

Rogers, A. and Pilgrim, D. (2005) A Sociology of Mental Health and Illness. Third Edition. Maidenhead: Open University Press.

Scott, M. (2008) WordSmith Tools Version 5. Liverpool: Lexical Analysis Software.

Seale, C., Ziebland, S. and Charteris-Black, J. (2007) Gender, cancer experience and internet use: A comparative keyword analysis of interviews and online cancer support groups. Social Science \& Medicine 62 (10): 2577-2590. http://dx.doi.org/ 10.1016/j.socscimed.2005.11.016
Smith, C., Adolphs, S., Harvey, K. and Mullany, L. (2014) Spelling errors and keywords in borndigital data: A case study using the Teenage Health Freak Corpus. Corpora 9 (2): 137-154. http://dx. doi.org/10.3366/cor.2014.0055

Suzuki, L., and Calzo, J. (2004) The search for peer advice in cyberspace: An examination of online teen bulletin boards about health and sexuality. Applied Developmental Psychology 25 (6): 685698. http://dx.doi.org/10.1016/j.appdev.2004.09. 002

Suler, J. (2004) The online disinhibition effect. CyberPsychology and Behavior 7 (3): 321-326. http://dx.doi.org/10.1089/1094931041291295

Treasure, J., Claudino, A. and Zucker, N. (2010) Eating disorders, The Lancet 375 (9714): 583-593. http:// dx.doi.org/10.1016/S0140-6736(09)61748-7

Louise Mullany is Associate Professor of Sociolinguistics at the University of Nottingham. She has published widely in the area of professional communication and her research primarily focuses on health and business settings. Address for correspondence: School of English, University of Nottingham, Nottingham, NG7 2RD, UK. Email: louise.mullany@ nottingham.ac.uk

Catherine Smith is a Research Fellow and Technical Officer at the Institute for Textual Scholarship and Electronic Editing (ITSEE) at the University of Birmingham. She was previously a Research Fellow in corpus linguistics at the University of Nottingham. Address for correspondence: ITSEE, Department of Theology and Religion, University of Birmingham, Edgbaston, Birmingham, B12 2TT, UK. Email: c.j.smith@bham.ac.uk

Kevin Harvey is Lecturer in Sociolinguistics at the University of Nottingham. His particular research interest is in the field of health communication from a corpus-linguistic and discourse-based approach. Address for correspondence: School of English, University of Nottingham, Nottingham, NG7 2RD, UK. Email: kevin.harvey@nottingham.ac.uk

Svenja Adolphs is Professor of Applied Linguistics at the University of Nottingham. Her research interests are in the areas of health communication, corpus linguistics, pragmatics and discourse analysis. School of English, University of Nottingham, Nottingham, NG7 2RD, UK. Email: svenja.adolphs@nottingham.ac.uk 
